
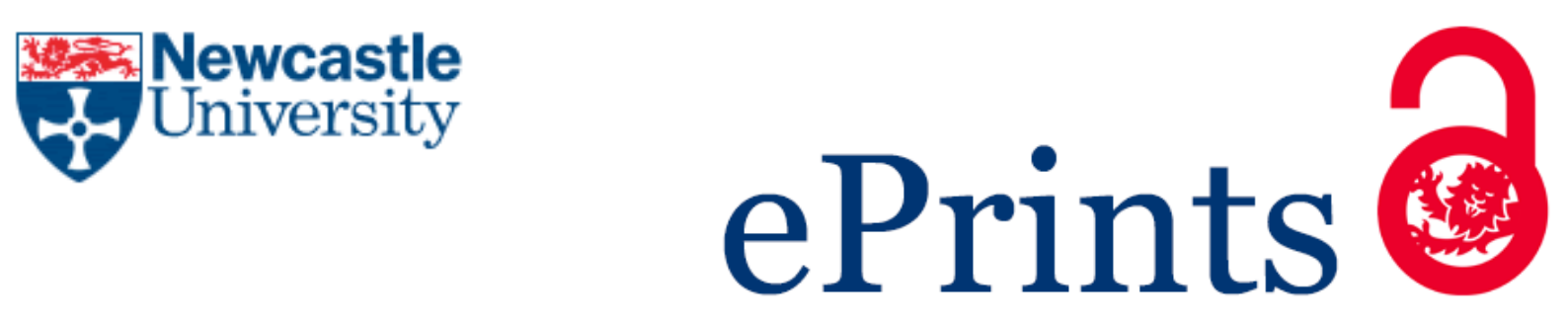

Rundle S, Halvorsrud K, Bizzarri N, Ratnavelu NDG, Fisher AD, Ang C, Bryant A, Naik R, Kucukmetin A. Sentinel node biopsy for diagnosis of pelvic lymph node involvement in early stage cervical cancer. Cochrane Database of Systematic Reviews 2017, 2017(12).

Copyright:

(C)The authors.

DOI link to article:

https://doi.org/10.1002/14651858.CD007925.pub2

Date deposited:

$11 / 01 / 2018$

Embargo release date:

18 December 2018 


\section{(E) Cochrane Library}

Cochrane Database of Systematic Reviews

\section{Sentinel node biopsy for diagnosis of pelvic lymph node involvement in early stage cervical cancer (Protocol)}

Rundle S, Halvorsrud K, Bizzarri N, Ratnavelu NDG, Fisher AD, Ang C, Bryant A, Naik R, Kucukmetin A

Rundle S, Halvorsrud K, Bizzarri N, Ratnavelu NDG, Fisher AD, Ang C, Bryant A, Naik R, Kucukmetin A. Sentinel node biopsy for diagnosis of pelvic lymph node involvement in early stage cervical cancer. Cochrane Database of Systematic Reviews 2017, Issue 12. Art. No.: CD007925.

DOI: 10.1002/14651858.CD007925.pub2.

www.cochranelibrary.com

Sentinel node biopsy for diagnosis of pelvic lymph node involvement in early stage cervical cancer (Protocol) Copyright @ 2017 The Cochrane Collaboration. Published by John Wiley \& Sons, Ltd. 
TABLE OF CONTENTS

HEADER . . . . . . . . . . . . . . . . . . . . . . . . . . . . . . . . . . . . . . . 1

ABSTRACT . . . . . . . . . . . . . . . . . . . . . . . . . . . . . . . . . . . . . . 1

BACKGROUND . . . . . . . . . . . . . . . . . . . . . . . . . . . . . . . . . . . .

Figure $1 . \quad$. . . . . . . . . . . . . . . . . . . . . . . . . . . . . . . . . . . . . 43

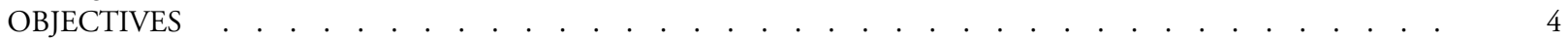

METHODS . . . . . . . . . . . . . . . . . . . . . . . . . . . . . . . . . . . . . . . 44

ACKNOWLEDGEMENTS . . . . . . . . . . . . . . . . . . . . . . . . . . . . . . . . . . . . . . . . .

REFERENCES . . . . . . . . . . . . . . . . . . . . . . . . . . . . . . . . . . . . . . . . . . 4

ADDITIONAL TABLES . . . . . . . . . . . . . . . . . . . . . . . . . . . . . . . . . . . . . . . . . . . . 9

APPENDICES . . . . . . . . . . . . . . . . . . . . . . . . . . . . . . . . . . . . . . . 414

WHATS NEW . . . . . . . . . . . . . . . . . . . . . . . . . . . . . . . . . . . . . 16

CONTRIBUTIONS OF AUTHORS . . . . . . . . . . . . . . . . . . . . . . . . . . . . . . . . . . . . . . . . $\quad$.

DECLARATIONS OF INTEREST . . . . . . . . . . . . . . . . . . . . . . . . . . . . . . . . . . . . . . . 17

SOURCES OF SUPPORT . . . . . . . . . . . . . . . . . . . . . . . . . . . . . . . . . . . . . . . . . 17

Sentinel node biopsy for diagnosis of pelvic lymph node involvement in early stage cervical cancer (Protocol)

Copyright $($ C 2017 The Cochran Collaboration. Published by John Wiley \& Sons, Ltd. 
[Diagnostic Test Accuracy Protocol]

\title{
Sentinel node biopsy for diagnosis of pelvic lymph node involvement in early stage cervical cancer
}

\author{
Stuart Rundle ${ }^{1}$, Kristoffer Halvorsrud ${ }^{2}$, Nicolo Bizzarri ${ }^{1}$, Nithya DG Ratnavelu ${ }^{1}$, Ann D Fisher ${ }^{1}$, Christine Ang ${ }^{1}$, Andrew Bryant ${ }^{3}$, \\ Raj Naik ${ }^{1}$, Ali Kucukmetin ${ }^{1}$ \\ ${ }^{1}$ Gynaecological Oncology, Northern Gynaecological Oncology Centre, Gateshead, UK. ${ }^{2}$ Centre for Psychiatry, Wolfson Institute of \\ Preventive Medicine, London, UK. ${ }^{3}$ Institute of Health \& Society, Newcastle University, Newcastle upon Tyne, UK \\ Contact address: Stuart Rundle, Gynaecological Oncology, Northern Gynaecological Oncology Centre, Queen Elizabeth Hospital, \\ Sheriff Hill, Gateshead, NE9 6SX, UK. stuart.rundle@gmail.com, stuart.rundle@nhs.net.
}

Editorial group: Cochrane Gynaecological, Neuro-oncology and Orphan Cancer Group.

Publication status and date: Edited (no change to conclusions), published in Issue 12, 2017.

Citation: Rundle S, Halvorsrud K, Bizzarri N, Ratnavelu NDG, Fisher AD, Ang C, Bryant A, Naik R, Kucukmetin A. Sentinel node biopsy for diagnosis of pelvic lymph node involvement in early stage cervical cancer. Cochrane Database of Systematic Reviews 2017, Issue 12. Art. No.: CD007925. DOI: 10.1002/14651858.CD007925.pub2.

Copyright (C) 2017 The Cochrane Collaboration. Published by John Wiley \& Sons, Ltd.

\begin{abstract}
A B S T R A C T
This is a protocol for a Cochrane Review (Diagnostic test accuracy). The objectives are as follows:

To assess the diagnostic accuracy of sentinel lymph node biopsy in the identification of lymph node involvement in patients with early stage cervical cancer (Stage IA2 to IIA).

We will first explore the impact of major factors for heterogeneity such as tumour size, FIGO stage and timing between application, detection of tracers, tracer substance used, surgical approach, experience of the operator and use of histological ultra-staging techniques. Then, we may consider other factors such as previous treatment to the cervix (including conisation), patient age and body mass index, as these have previously been suggested as possible factors associated with success or failure of sentinel node identification (Sinno 2014; Tanner 2015; Wuntakal 2015).
\end{abstract}

\section{B A C K G R O U N D}

\section{Target condition being diagnosed}

Cervical cancer is the fourth most common cancer in women, and the seventh overall, with an estimated 528,000 new cases and 266,000 deaths attributed to cervical cancer worldwide in 2012, accounting for $7.5 \%$ of all female cancer deaths (GLOBOCAN 2012). A large majority (around $85 \%$ ) of the global burden occurs in less-developed regions, where it accounts for almost $12 \%$ of all female cancers. Cervical cancer remains the most common cancer in women in Eastern and Middle Africa. This fact reflects the differences in the availability of effective Human Papilloma Virus (HPV) vaccination and cervical screening programmes as well as effective treatments. In Europe, approximately $60 \%$ of women with cervical cancer are alive five years after diagnosis (EUROCARE 5a).

Cervical cancer is staged according to the FIGO system (Benedet 2003), which is based on findings from clinical examination (Table 1). Stage I disease is confined to the cervix. This is subdivided into stage IA and IB. Stage IA can only be seen with a microscope, while IB can usually be seen with the naked eye. Stage IA is further 
divided into Stage IA1 and stage IA2. Stage IA1 means the cancer has invaded less than $3 \mathrm{~mm}$ into the cervical tissue and it is less than $7 \mathrm{~mm}$ wide. Stage IA2 means that the cancer has invaded between $3 \mathrm{~mm}$ and $5 \mathrm{~mm}$ deep but is still less than $7 \mathrm{~mm}$ wide. If the cancer is bigger than Stage IA2, but still confined to the cervix, it would be classified as stage IB. Stage IB again can be divided into IB1 and IB2 where IB1 represents cancers that are less than $4 \mathrm{~cm}$ across while IB2 are tumours larger than $4 \mathrm{~cm}$.

For Stage II disease, the tumour has spread to the upper part of the vagina (stage IIA) or to the tissues around the cervix, but not reaching the pelvic side wall (stage IIB). Stage III represents disease that has reached the lower part of the vagina (IIIA) or the pelvic side wall (IIIB) and Stage IV represents disease that has spread to the other organs such as the bladder or the bowel. Although lymph node involvement does not contribute to the FIGO staging, it is one of the most important factors in prognosis and determining treatment. For early disease (stage IB to IIA), about $95 \%$ of women can expect to be alive after five years ( Kim 2000). However, if the tumour had spread to the lymph glands in the pelvis, the expected survival at five years drops to about $78 \%$. Furthermore, data suggest that extra-pelvic lymph node metastases further impacts on survival (Kim 2000). In this review, women with FIGO stage IA2 to IIA cervical cancer will be the population of interest as this group of women would usually be candidates for systematic pelvic lymphadenectomy as part of the surgical treatment of their cervical cancers (Rationale).

\section{Index test(s)}

The detection of the sentinel node in cervical cancer involves subepithelial injection of a radioactive tracer substance e.g. 99mTC (technetium) -labelled colloid, blue dye (e.g. Patent Blue or methylene blue) or indocyanine green (ICG) into the cervix before the operation. The spread of the tracer substance would mimic the cancer cells and follow the lymphatic drainage around the cervix. The tracer substance would localise to the lymph nodes that represent the first lymph nodes in the lymphatic chain to which cancer cells would spread. If radioactive tracer substance is used, the total radioactive dose varies between $10 \mathrm{MBq}$ to $111 \mathrm{MBq}$, depending on the time interval between injection and surgery (Lantzsch 2001; Rhim 2002), and a scan to look at the lymphatic system (lymphoscintigraphy) may be performed after injection of the radioactive tracer to map the location of the sentinel lymph nodes (Bats 2007; Darai 2007). Preoperative lymphoscintigraphy gives some guidance to the surgeons with regard to the location of the sentinel lymph nodes. If blue dye or ICG are used, the tracer substance is injected into the cervix at the beginning of surgery. Intraoperatively, blue dye stained lymph nodes can be visualised after opening the retroperitoneum, and nodes with radioactive uptake can be detected with a gamma camera. ICG is visualised using near-infrared fluorescence (NIR) and can be detected transperitoneally prior to opening the retroperitoneum. Lymph nodes that are stained with ICG or blue dye or nodes and are radioactive are then removed as sentinel lymph nodes (Schneider 2007). The sentinel node is then submitted for histological analysis. Histological analysis may include ultra-staging techniques to improve the detection of smaller cancer cell deposits (Cibula 2012). If cancer cells are present, the node is considered as positive. Intraoperative frozen section histological analysis of sentinel lymph nodes has previously been described. This technique, however, has been shown to be less reliable for the diagnosis of lymph node metastases than analysis of fixed histological specimens (Bats 2011).

Prospective and retrospective data suggest that sentinel lymph node assessment can achieve a greater than $90 \%$ sensitivity and $100 \%$ specificity in predicting lymph node status in women with cervical cancer (Cibula 2012; Kadkhodayan 2015; Lecuru 2011; Selman 2008; Tax 2015; Wang 2015). However, if the procedure only includes the injection of blue dye without the use of a radioactive tracer or vice versa, the detection rate and sensitivity are significantly reduced when compared to the combined technique (Van de Lande 2007). Currently, the technique of sentinel lymph node detection is mainly confined to clinical trials, though reports of this technique being incorporated into standard practice in early stage disease are emerging (Devaja 2012; Gortzak-Uzan 2010; Niikura 2012; Wuntakal 2015). In clinical trials, regardless of the status of the sentinel node, a systematic lymphadenectomy would still be carried out in order to avoid wrong clinical management in the case of a false-negative result. Ideally, if sentinel node assessment is accurate, it can replace the need for a systematic lymphadenectomy and its associated risks (see Rationale). However, in the situation where there is a false-negative result (i.e. when there were positive lymph nodes but the sentinel lymph node was negative), omission of a systematic lymphadenectomy would mean that the positive lymph nodes would remain in the woman and she would be falsely diagnosed as "lymph node negative". This would lead to omission of chemo-irradiation as part of her treatment and might lead to a significant negative impact on her overall prognosis.

\section{Role of the index test}

The role of the index test is to predict accurately lymph node metastases in women with early stage cervical cancer so that the need for further treatment can be determined whilst the extent of surgery can be reduced.

\section{Clinical pathway}

Clinical pathway for women with early stage cervical cancer ( Figure 1) 
Figure I.

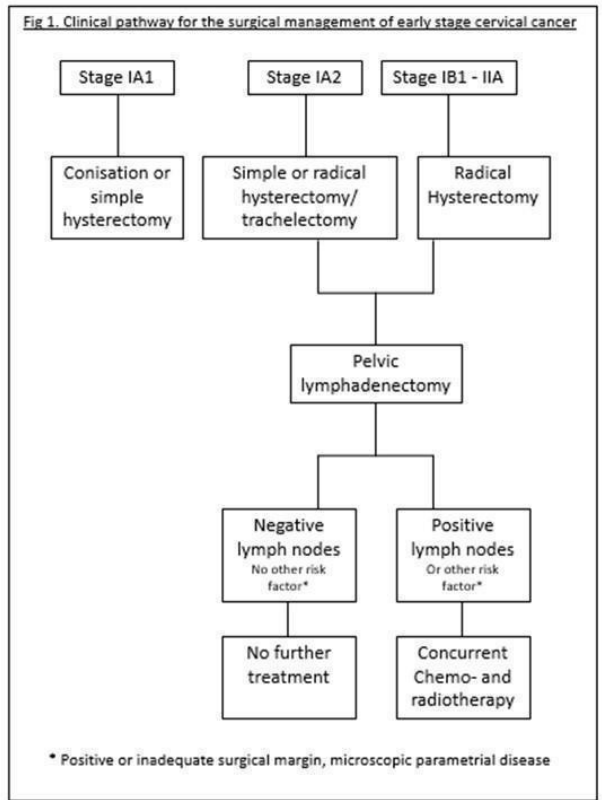

\section{Alternative test(s)}

Radiological Imaging techniques have been used to assess lymph node status before primary surgery. These have the advantage of being non-invasive, but their sensitivities appeared to be limited. Computer tomography (CT) and magnetic resonance imaging (MRI) rely on size and morphological criteria to recognise lymph node metastasis, and small metastatic nodes may be missed (Boss 2000; Hricak 1993; Schneider 2007; Yang 2000). A systematic review of 57 articles between 1985 and 2002 showed sensitivities for lymph node involvement in women with cervical cancer for MRI and CT of $60 \%$ and 43\%, respectively (Bipat 2003). Positron emission tomography (PET) gives functional imaging of cancer cells. Used alone or in combination with CT, it has been applied in the staging assessment of various gynaecological cancers. High sensitivity and specificity in detection of para-aortic metastases in advanced or recurrent cervical cancer have been reported (Rose 1999), but its role in predicting pelvic node involvement in early disease of gynaecological cancers in general is still uncertain (Lai 2007). A meta-analysis involving 445 women with primary cervical cancer in eight studies showed that the sensitivity of PET in predicting lymph node status was $74.7 \%$ and the specificity was $97.6 \%$ (Selman 2008). The sensitivities for imaging techniques in the detection of the sentinel nodes in cervical cancer are not high enough to be clinically useful.

\section{Rationale}

For early disease (Stage I to Stage IIA), surgery is the most common treatment method. In very early disease (IA1 and IA2), this can be limited to removal of the part of the cervix affected by cancer or by a simple, or standard hysterectomy (Bouchard-Fortier 2014). For Stage IB disease or above, a radical hysterectomy which involves a hysterectomy together with removal of tissues around the cervix is the traditional treatment of choice and this may be either as an open abdominal or as a key-hole operation (Kucukmetin 2013). Radical hysterectomy may be followed by radiotherapy or a combination of chemotherapy and radiotherapy for women with stage IB to IIA cervical cancer, though the impact of this adjuvant treatment on overall survival is thought to be limited (Rogers 2012). For higher stages (Stage IIB or above), the main treatment would be chemo-irradiation instead of surgery. Lymph node metastasis has been found in less than $1 \%$ of FIGO Stage IA1 disease (Elliott 2000), but this increases to $9 \%$ in Stage IA2 disease (Takeshima 1999). As there is a higher chance of lymph node metastasis in Stage IA2 or above, pelvic lymph node dissection forms part of the standard treatment for Stage IA2 to IIA cervical cancer. The current reference standard for determining lymph node spread is by a systematic lymphadenectomy where all the lymph nodes along the major vessels in the pelvis are removed for histological assessment. However, such dissection is associated with potential morbidities such as formation of lymphocysts and lymphoedema in up to $20 \%$ of women (Ryan 2003), and the risk of these morbidities may be significantly reduced if sentinel lymph node excision were to replace systematic lymphadenectomy (Achouri 2013). 
Considering the low incidence of lymph node involvement, most women, particularly those with very early disease, would have undergone a systematic dissection, with its associated risks, unnecessarily. Furthermore, in situations where lymph nodes are histologically confirmed to be involved, chemo-irradiation would be offered. In these patients, systematic node dissection is of uncertain additional benefit. Therefore, different ways of assessing lymph node involvement have been explored.

Imaging techniques such as CT scans, MRI and PET are noninvasive methods that can be used to detect enlarged lymph nodes. However, these methods cannot accurately determine whether the enlarged nodes are due to cancer involvement or due to a reactive response to local infection or an inflammatory response to the malignant lesion. Alternatively, the concept of sentinel node assessment has been investigated. The sentinel lymph node is the first lymph node to which the tumour cells would spread via the lymphatics. The histological status of the sentinel node is presumed to be representative of all other lymph nodes draining the same anatomical site: that is, if this sentinel node is negative histologically; the remaining lymph nodes draining the same region are assumed to be also negative. Since there is a possibility for sentinel node biopsy to replace a systematic lymphadenectomy in clinical practice (whereas the various imaging techniques are unlikely to do so), this review will concentrate on assessing the diagnostic accuracy of sentinel node biopsy alone.

\section{O B J E C T I V E S}

To assess the diagnostic accuracy of sentinel lymph node biopsy in the identification of lymph node involvement in patients with early stage cervical cancer (Stage IA2 to IIA).

\section{Secondary objectives}

We will first explore the impact of major factors for heterogeneity such as tumour size, FIGO stage and timing between application, detection of tracers, tracer substance used, surgical approach, experience of the operator and use of histological ultra-staging techniques. Then, we may consider other factors such as previous treatment to the cervix (including conisation), patient age and body mass index, as these have previously been suggested as possible factors associated with success or failure of sentinel node identification (Sinno 2014; Tanner 2015; Wuntakal 2015).

\section{METHODS}

\section{Criteria for considering studies for this review}

\section{Types of studies}

Included studies may be either prospective or retrospective designs comparing sentinel node biopsy with the reference standard. We will exclude studies reporting insufficient data for accurate identification of the target population or for the construction of a twoby-two table, and case-control studies. We will also exclude studies with fewer than 10 cases.

\section{Participants}

Women diagnosed with early stage (IA2 to IIA) cervical cancer on the basis of loop biopsy (for microscopic disease) or examination under anaesthesia and biopsy with or without cystoscopy. We will consider all settings and all ages in this review. We will include studies that include at least $80 \%$ of women with early stage disease, as it is expected that some studies will have small percentages of women with Stage IIB, III and IV disease.

\section{Index tests}

Sentinel lymph node biopsy. Studies should specify the technique used, including:

- whether radioactive tracer, blue dye, ICG or a combination of these were used;

- technique of injection of tracer substance, including timing of injection, amount of tracer used and location of injection;

- exact technique of detection of tracer substance (e.g. whether a preoperative scintigram was done, whether the intraoperative detection was done via an open, laparoscopic or robotic approach and for studies which use ICG, which nearinfrared fluorescence (NIR) system was used to detect the lymph node);

- definition of what is regarded as a sentinel node;

- the histological method of assessment of the sentinel node including details of any ultra-staging techniques used.

A sentinel node should be defined as a lymph node sending a radioactive signal with an activity higher than 10 -fold above background radiation level, a node that appears blue intraoperatively or, in the case of ICG-NIR, a node that appears to fluoresce when specialised near-infrared equipment is used for detection. The sentinel node identified should be removed and submitted for histological examination with at least haematoxylin and eosin ( $\mathrm{H} \& \mathrm{E}$ ) staining, including those at extra-pelvic sites. If the sentinel node is found to be malignant by histological examination, it is defined as a positive sentinel node. If a sentinel node is detected but histologically did not show any malignancy, it may be subjected to ultra-staging techniques. If no malignancy is detected in the lymph node, it is defined as a negative node. Results of the studies need to report whether sentinel nodes are detected unilaterally or bilaterally. If a sentinel node cannot be identified by the tracer substance used, then it is defined as 'failure to detect sentinel nodes'. In the case of failure to detect sentinel nodes either unilaterally 
or bilaterally, the studies should report whether a side-specific or bilateral systematic pelvic lymphadenectomy was undertaken. In the situation where lymph node metastases is detected by systematic lymphadenectomy and not by a sentinel lymph node, it should be specified whether the positive lymph nodes identified by systematic lymphadenectomy are on the side that no sentinel node was detected; or that a sentinel node was identified on that side and was negative. We would take these situations into account in conducting the analysis, as they may have important implications on the true accuracy of the test.

\section{Target conditions}

Pelvic lymph node metastases in early stage cervical cancer (IA2 to IIA).

\section{Reference standards}

Systematic pelvic lymphadenectomy, laparoscopic or open, followed by standard histological assessment of surgical specimen. Systematic pelvic lymphadenectomy should include removal of all the obturator, internal and external iliac and common iliac nodes, with or without para-aortic nodes. The removed surgical specimen would be subjected to standard histological assessment with at least $\mathrm{H} \& \mathrm{E}$ staining. If any of the removed nodes showed cancer metastasis histologically, the reference standard is considered positive. Studies should specify how many lymph nodes at each of the above sites were removed. Studies should also specify whether the reference standard result is positive for one side or both sides of the pelvis.

\section{Search methods for identification of studies}

\section{Electronic searches}

We will search the following electronic databases.

- MEDLINE (OvidSP) (1946-current)

- Embase (OvidSP) (1980-current)

We will use the search strategy specified in Appendix 1 to search MEDLINE, which reflects the key concepts of the review to include recent reports that incorporate ICG-NIR technology: index test (sentinel lymph node biopsy) AND target condition (pelvic lymph node metastases in early stage cervical cancer). We will design a similarly structured search strategy using search terms appropriate for Embase.

We will not apply language restrictions to the electronic searches and we will arrange for translations, where possible, if relevant studies are found in languages other than English.

\section{Searching other resources}

We will check the reference lists of all studies deemed to be relevant from the electronic searches for additional potentially relevant studies.

We will also search the following databases for related systematic reviews, and we will check the reference lists of those that are relevant for additional studies.

- DARE (Database of Abstracts of Reviews of Effects)

www.york.ac.uk/inst/crd/crddatabases.htm\#DARE

- MEDION (Meta-Analyses van Diagnostisch Onderzoek) www.mediondatabase.nl

- HTA Database (Health Technology Assessments Database) www.york.ac.uk/inst/crd/crddatabases.htm\#HTA

- ARIF (Aggressive Research Intelligence Facility) www.arif.bham.ac.uk

We will use all studies identified as relevant as seeds in PubMed to search for additional studies using the related articles feature.

We will also use the relevant studies as seeds in the Science Citation Index (ISI Web of Knowledge) and Google Scholar (www.scholar.google.com) to determine whether articles citing these studies are also relevant.

We will handsearch abstract books of meetings of the International Gynaecological Cancer Society, the European Society of Gynaecological Oncology and the Society of Gynecologic Oncologists from 2000 to latest edition to identify unpublished studies.

Where necessary, we will contact the main investigators of relevant ongoing studies for further information.

If necessary, we will also contact authors of relevant studies to ask if they know of further data which may or may not have been published.

\section{Data collection and analysis}

\section{Selection of studies}

We will download all titles and abstracts retrieved by electronic searching to the reference management database Endnote. We will remove duplicates and two review authors (SR, NB) will independently examine the remaining references. We will exclude those studies which clearly do not meet the inclusion criteria, and obtain copies of the full text of potentially relevant references. Two review authors (SR, NB) will assess the eligibility of retrieved papers independently. We will resolve disagreements, if possible, between SR and NB, and, if necessary, involve a third review author ( NR, $\mathrm{AK}$, or $\mathrm{RN}$ ). We will document reasons for exclusion.

\section{Data extraction and management}

We will extract data on the following items. 
- Author, year of publication and journal (including

language).

- Country.

- Settings.

- Inclusion and exclusion criteria.

- Study design.

- Study population.

- Number of patients.

- Definition of cervical pathology (by punch biopsy, loop biopsy etc).

- Any triage or add-on tests done in addition to the index test.

- Experience of the operator.

- Cervical cancer details:

- FIGO stage;

o size of tumour;

- histological cell type;

- lymphovascular space involvement;

- previous treatment details such as loop biopsy, laser treatment etc.

- Reference standard and performance of the reference standard:

- laparoscopic or open;

- lymph node yield (and site);

- histological assessment method.

- Performance of the index test:

$\circ$ for sentinel lymph node biopsy:

$\diamond$ tracer substance used, amount and dilution;

$\diamond$ method of application;

$\diamond$ timing of application;

$\diamond$ method of detection;

$\diamond$ histological assessment method.

- Reporting of results:

o sentinel lymph node detection rate for unilateral and bilateral nodes;

$\circ$ in false-negative cases, are the positive nodes by reference standard on the side where there is failure to detect sentinel nodes?

$\circ$ any adverse effect arising from the index test;

$\circ$ any adverse effect arising from the reference standard.

- QUADAS-2 items (see below).

- Data for two-by-two table.

Two review authors (SR, NB) will extract data independently onto a data abstraction spreadsheet specially designed for the review. We will resolve differences between review authors by discussion or by appeal to a third review author (NR, AKM, or RN) if necessary. We will use two primary diagnostic studies to pilot the data abstraction spreadsheet (including the quality assessment).

\section{Assessment of methodological quality}

Two review authors (SR and NB) will independently perform the quality assessment. In case of disagreement, a consensus meeting will be held. In case of persisting disagreement, we will refer the issue to a third review author (NR, AKM, RN or KH). We will assess study quality using the QUADAS-2 list (Whiting 2011). We will report the results in detail in tabular and graphical form, and summarise them in the text. We will report methodological quality graphically by showing the percentage of studies that did or did not fulfil each item. We will also produce tables showing the results of each quality item for all individual studies.

We will assess the quality items derived from the QUADAS-2 tool using the methodology stated in Table 2. The QUADAS2 tool, tailored specifically for use in this review omits the core quality questions "was a case-control design avoided?" and "if a threshold was used, was it pre-specified?". These quality items are of limited applicability to this review due to the proposed inclusion of all study designs prior to quality assessment and the dichotomous nature of the index test and reference standard result. Additional QUADAS-2 quality questions were included within the index test domain: "Did the study provide clear information about which cases were considered to be a 'failure to detect sentinel nodes'?" and "Had test operators had appropriate training?". These signalling questions represent important quality assessments for the performance and interpretation of the index test result.

\section{Statistical analysis and data synthesis}

We will input data from two-by-two tables into Review Manager 2014 (5.3.5) for the calculations of sensitivity and specificity for each study. We will present individual study results graphically by plotting estimates of sensitivities and specificities in receiver operating characteristic (ROC) space. If more than one threshold is reported, we will choose the two-by-two table for the threshold most widely reported in the included studies to incorporate in the meta-analysis. We will use the statistical package Stata 14.1 (College Station, TX: StataCorp, 2015) to meta-analyse pairs of sensitivity and specificity using a bivariate random-effects approach (Reitsma 2005). As we anticipate little variation in thresholds between studies (since the histological confirmation of the presence or absence of lymph node metastases yields a dichotomous result), we will calculate summary estimates of sensitivity and specificity, while correctly dealing with any correlation that might exist between sensitivity and specificity.

Co-variates can be incorporated in the bivariate model in order to examine the effect of potential sources of heterogeneity on sensitivity and specificity. The results of the bivariate model will be used to calculate likelihood ratios. To illustrate the findings, the negative predictive value will be presented for a range of plausible values of the prevalence of pelvic lymph node involvement; e.g. the median and inter-quartile range of prevalence in included studies. It is not anticipated that a false-positive result will be encountered 
as a positive result in the index test is regarded as a true-positive result, even in the case where the reference test yields a negative result. This arises from the assumption that a positive sentinel lymph node would have been included in the lymphadenectomy specimen (reference test) had the sentinel lymph node procedure (index test) not been carried out. Therefore, positive predictive values will not be calculated.

We will treat extra-pelvic sentinel node involvement (e.g. in the para-aortic region) in the same way as for pelvic sentinel nodes, i.e. removed and sent for histological assessment. Therefore, we will include extra-pelvic sentinel nodes in the statistical analysis as part of the overall sentinel node yield.

\section{Investigations of heterogeneity}

We will investigate heterogeneity by visual examination of forest plots of sensitivities and specificities and through a visual examination of the ROC plot of the raw data. We will use bivariate models to estimate imprecision by which sensitivity and specificity have been measured within each study and variation beyond chance in sensitivity and specificity between studies. We expect the results of the index test to vary according to (i) the sentinel node procedure (use of radioactive tracer, blue dye, ICG or a combination of these), and (ii) whether the approach was open laparoscopic or robotic, (iii) whether ultra-staging techniques were used in the histological analysis of the sentinel lymph nodes.

We will investigate this by including these factors as a co-variate in meta-regression in Stata 14.1 (College Station, TX: StataCorp, 2015), where we will test for differences between groups and obtain relative measures of test accuracy such as relative diagnostic odds ratios. We will therefore interpret our findings in the light of possible heterogeneity between different methods of detection and between different subgroups of patients as specified above (see Secondary objectives). Any unexplained variability between studies will be interpreted using clinical judgement.

\section{Sensitivity analyses}

If sufficient data are available, we will explore possible sources of bias by undertaking sensitivity analyses based on the overall quality assessment (QUADAS-2). We will omit studies that did not satisfy quality criteria and scored 'no' or 'unclear' for all QUADAS-2 domains in sensitivity analyses. If permitted by the variability of included studies, we will also conduct sensitivity analysis based on the type of study design, for example whether retrospective or prospective.

\section{ACKNOWLEDGEMENTS}

The authors would like to acknowledge Karen K L Chan and Javier Zamora who contributed to the authorship of the previous version of this protocol (Chan 2009).

We thank Jo Morrison for clinical and editorial advice, Jo Platt for designing the search strategy, and Gail Quinn, Clare Jess and Tracey Harrison for their contributions to the editorial process. .

This project was supported by the National Institute for Health Research, via Cochrane Infrastructure funding to the Cochrane Gynaecological, Neuro-oncology and Orphan Cancer Group. The views and opinions expressed therein are those of the authors and do not necessarily reflect those of the Systematic Reviews Programme, NIHR, NHS or the Department of Health.

\section{RE F E R E N C E S}

\section{Additional references}

\section{Achouri 2013}

Achouri A, Huchon C, Bats AS, Bensaid C, Nos C, Lecuru

F. Complications of lymphadenectomy for gynecologic cancer. European Journal of Surgical Oncology 2013;39(1): $81-6$.

\section{Bats 2007}

Bats AS, Clément D, Larousserie F, Lefrère-Belda MA, Faraggi M, Froissart M, et al. Sentinel lymph node biopsy improves staging in early cervical cancer. Gynecologic Oncology 2007;105(1):189-93.

\section{Bats 2011}

Bats AS, Buénerd A, Querleu D, Leblanc E, Daraï E, Morice P, et al. SENTICOL collaborative group. Diagnostic value of intraoperative examination of sentinel lymph node in early cervical cancer: a prospective, multicenter study. Gynecological Oncology 2011;123(2):230-5.

\section{Benedet 2003}

Benedet JL, Odicino F, Maisonneuve P, Beller U, Creasman WT, Heintz AP. Carcinoma of the cervix uteri. International Journal of Gynaecology and Obstetrics 2003;83(Suppl 1): 41-78.

\section{Bipat 2003}

Bipat S, Glas AS, van der Velden J, Zwinderman AH, Bossuyt PM, Stoker J. Computed tomography and magnetic resonance imaging in staging of uterine cervical carcinoma: a systematic review. Gynecologic Oncology 2003;91(1): 59-66.

\section{Boss 2000}

Boss EA, Barentsz JO, Massuger LF. The role of MR imaging in invasivecervical carcinoma. European Radiology 2000;10(2):256-70.

Bouchard-Fortier 2014

Bouchard-Fortier G, Reade CJ, Covens A. Non-radical 
surgery for small early-stage cervical cancer. Is it time?. Gynecologic Oncology 2014;132(3):624-7.

\section{Cibula 2012}

Cibula D, Abu-Rustum NR, Dusek L, Slama J, Zikán M, Zaal A, et al. Bilateral ultrastaging of sentinel lymph node in cervical cancer: lowering the false-negative rate and improving the detection of micrometastasis. Gynecologic Oncology 2012;127(3):462-6.

Darai 2007

Darai E, Lavoue V, Rouzier R, Coutant C, Barranger E, Bats A-S. Contribution of the sentinel node procedure to tailoring the radicality of hysterectomy for cervical cancer. Gynecologic Oncology 2007;106(1):251-6.

\section{Devaja 2012}

Devaja O, Mehra G, Coutts M, Montalto SA, Donaldson J, Kodampur M, et al. A prospective single-center study of sentinel lymph node detection in cervical carcinoma: is there a place in clinical practice?. Internaltional Journal of Gynecological Cancer 2012;22(6):1044-9.

\section{Elliott 2000}

Elliott P, Coppleson M, Russell P. Early invasive (FIGO stage IA) carcinoma of the cervix: a clinico-pathologic study of 476 cases. International Journal of Gynecological Cancer 2000;10(1):42-52.

\section{EUROCARE 5a}

De Angelis R, Sant M, Coleman MP, Francisci S, Baili P, Pierannunzio D, et al: EUROCARE-5 Working Group. Cancer survival in Europe 1999-2007 by country and age: results of EUROCARE--5-a population-based study. Lancet 2014;15(1):23-34.

\section{GLOBOCAN 2012}

Ferlay J, Soerjomataram I, Ervik M, Dikshit R, Eser S, Mathers C, et al. GLOBOCAN 2012 v1.0, Cancer Incidence and Mortality Worldwide: IARC CancerBase No. 11. Lyon, France: International Agency for Research on Cancer; 2013. Available from: http://globocan.iarc.fr, accessed on 29/01/2017.

\section{Gortzak-Uzan 2010}

Gortzak-Uzan L, Jimenez W, Nofech-Mozes S, Ismiil N, Khalifa MA, Dubé V, et al. Sentinel lymph node biopsy vs. pelvic lymphadenectomy in early stage cervical cancer: is it time to change the gold standard?. Gynecological Oncology 2010;116:28-32.

\section{Hricak 1993}

Hricak H, Quivey JM, Campos Z. Carcinoma of the cervix: Predictive value of clinical and magnetic resonance (MR) imaging assessment ofprognostic factors. International Journal of Radiation Oncology, Biology, Physics 1993;27: 791-801.

\section{Kadkhodayan 2015}

Kadkhodayan S, Hasanzadeh M, Treglia G, Azad A, Yousefi Z, Zarifmahmoudi L, et al. Sentinel node biopsy for lymph nodal staging of uterine cervix cancer: a systematic review and meta-analysis of the pertinent literature. European Journal of Surgical Oncology 2015;41(1):1-20.
Kim 2000

Kim SM, Choi HS, Byun JS. Overall 5-year survival rate and prognostic factors in patients with stage IB and IIA cervical cancer treated by radical hysterectomy and pelvic lymph node dissection. International Journal of Gynecological Cancer 2000;10(4):305-12.

\section{Kucukmetin 2013}

Kucukmetin, A. Biliatis, I. Naik, R. Bryant, A. Laparoscopically assisted radical vaginal hysterectomy versus radical abdominal hysterectomy for the treatment of early cervical cancer. Cochrane Database of Systematic Reviews 2013, Issue 10. [DOI: 10.1002/ 14651858.CD006651.pub3

\section{Lai 2007}

Lai CH, Yen TC, Chang TC. Positron emission tomography imaging for gynecologic malignancy. Current Opinion in Obstetrics and Gynecology 2007;19(1):37-41.

\section{Lantzsch 2001}

Lantzsch T, Wolters M, Grimm J. Sentinel node procedure in Ib cervical cancer: a preliminary series. British Journal of Cancer 2001;85(6):791-4.

\section{Lecuru 2011}

Lécuru F, Mathevet P, Querleu D, Leblanc E, Morice P, Daraï E, et al. Bilateral negative sentinel nodes accurately predict absence of lymph node metastasis in early cervical cancer: results of the SENTICOL study. Journal of Clinical Oncology 2011;29(13):1686-91.

\section{Niikura 2012}

Niikura H, Okamoto S, Otsuki T, Yoshinaga K, Utsunomiya $\mathrm{H}$, Nagase S, et al. Prospective study of sentinel lymph node biopsy without further pelvic lymphadenectomy in patients with sentinel lymph node-negative cervical cancer. Int J Gynecol Cancer 2012; 22:1244-1250.. Internaltional Journal of Gynecological Cancer 2012;22:1244-50.

\section{Reitsma 2005}

Reitsma JB, Glas AS, Rutjes AW, Scholten RJ, Bossuyt $\mathrm{PM}$, Zwinderman AH. Bivariate analysis of sensitivity and specificity produces informative summary measures in diagnostic reviews. Journal of Clinical Epidemiology 2005; 58:982-90.

\section{Review Manager 2014 [Computer program]}

Nordic Cochrane Centre, The Cochrane Collaboration. Review Manager (RevMan). Version 5.3.5. Version 5.3. Copenhagen: Nordic Cochrane Centre, The Cochrane Collaboration, 2014.

\section{Rhim 2002}

Rhim CC, Park JS, Bae SN, Namkoong SE. Sentinel node biopsy as an indicator for pelvic nodes dissection in early stage cervical cancer. Journal of Korean Medical Science 2002;17(4):507-11.

\section{Rogers 2012}

Rogers L, Siu SSN, Luesley D, Bryant A, Dickinson HO. Radiotherapy and chemoradiation after surgery for early cervical cancer. Cochrane Database of Systematic Reviews 2012, Issue 5. [DOI: 10.1002/14651858.CD007583.pub3 
Rose 1999

Rose PG, Adler LP, Rodriguez M, Faulhaber PF, AbdulKarim FW, Miraldi F. Positron emission tomography for evaluatingpara-aortic nodal metastasis in locally advanced cervical cancer before surgical staging: a surgicopathologic study. Journal of Clinical Oncology 1999;17:41-5.

Ryan 2003

Ryan M, Stainton MC, Slaytor EK, Jaconelli C, Watts S, Mackenzie P. Aetiology and prevalence of lower limb lymphoedema following treatment for gynaecological cancer. Australian and New Zealand Journal of Obstetrics and Gynaecology 2003;43(2):148-51.

Schneider 2007

Schneider A. The sentinel concept in patients with cervical cancer. Journal of Surgical Oncology 2007;96(4):337-41.

\section{Selman 2008}

Selman TJ, Mann C, Zamora J, Appleyard TL, Khan K. Diagnostic accuracy of tests for lymph node status in primary cervical cancer: a systematic review and metaanalysis. Canadian Medical Association Journal 2008;178 (7):855-62.

\section{Sinno 2014}

Sinno AK, Fader AN, Roche KL, Giuntoli RL 2nd, Tanner EJ. A comparison of colorimetric versus fluorometric sentinel lymph node mapping during robotic surgery for endometrial cancer. Gynecological Oncology 2014;134(2): 281-6.

\section{Takeshima 1999}

Takeshima N, Yanoh K, Tabata T, Nagai K, Hirai Y, Hasumi $\mathrm{K}$. Assessment of the revised International Federation of Gynecology and Obstetrics staging for early invasive squamous cervical cancer. Gynecologic Oncology 1999;74(2): 165-9.

\section{Tanner 2015}

Tanner EJ, Sinno AK, Stone RL, Levinson KL, Long KC, Fader AN. Factors associated with successful bilateral sentinel node mapping in endometrial cancer. Gynecological Oncology 2015;138:542-7.
Tax 2015

Tax C, Rovers MM, de Graaf C, Zusterzeel PL, Bekkers RL. The sentinel node procedure in early stage cervical cancer, taking the next step; a diagnostic review. Gynecological Oncology 2015;139(3):559-67.

Van de Lande 2007

van der Lande J, Torrenga B, Raijmakers P, Hoekstra O, van Baal M, Brölmann H, et al. Sentinel lymph node detection in early stage uterinecervix carcinoma: A systematic review. Gynecologic Oncology 2007;106(3):604-13.

Wang 2015

Wang XJ, Fang F, Li YF. Sentinel-lymph-node procedures in early stage cervical cancer: a systematic review and metaanalysis. Medical Oncology 2015;32(1):385.

\section{Whiting 2011}

Whiting PF, Rutjes AW, Westwood ME, Mallett S, Deeks JJ, Reitsma JB, et al. QUADAS-2 Group. QUADAS-2: a revised tool for the quality assessment of diagnostic accuracy studies. Annals of Internal Medicine 2011;155(8):529-36.

\section{Wuntakal 2015}

Wuntakal R, Papadopoulos AJ, Montalto SA, Perovic M, Coutts M, Devaja O. Location of sentinel lymph node in cervical carcinoma and factors associated with unilateral detection. International Journal of Gynecological Cancer 2015;25(9):1663-8.

Yang 2000

Yang WT, Lam WW, Yu MY. Comparison of dynamic helical CT and dynamic MR imaging in the evaluation of pelvic lymph nodes in cervical carcinoma. American Journal of Roentgenology 2000;175:759-66.

\section{References to other published versions of this review}

\section{Chan 2009}

Chan KKL, Ang C, Bryant A, Zamora J, Naik R. Sentinel node biopsy for diagnosis of pelvic lymph node involvement in early stage cervical cancer. Cochrane Database of Systematic Reviews 2009, Issue 3. [DOI: 10.1002/ 14651858.CD007925

* Indicates the major publication for the study

\section{ADDITIONAL TABLES}

Table 1. FIGO stage classifications

FIGO classification for cervical cancer

\section{STAGE CHARACTERISTICS}


Table 1. FIGO stage classifications (Continued)

IA Invasive cancer identified only microscopically. All gross lesions, even with superficial invasion, are stage IB cancers. Invasion is limited to a measured stromal invasion with a maximal depth of $5.0 \mathrm{~mm}$ and a horizontal extension of not $>7.0 \mathrm{~mm}$. Depth of invasion should not be $>5.0 \mathrm{~mm}$ taken from the base of the epithelium, either surface or glandular, from which it originates. Vascular space involvement, either venous or lymphatic, should not alter the staging

$\mathbf{I A}_{1} \quad$ Measured stromal invasion of not $>3.0 \mathrm{~mm}$ in depth and extension of not $>7.0 \mathrm{~mm}$

$\mathbf{I A}_{2}$ Measured stromal invasion of $>3.0 \mathrm{~mm}$ and not $>5.0 \mathrm{~mm}$ with an extension of not $>7.0 \mathrm{~mm}$

IB Clinical lesions confined to the cervix or preclinical lesions $>$ IA

$\mathbf{I B}_{1} \quad$ Clinical lesions not $>4 \mathrm{~cm}$ in size.

$\mathbf{I B}_{2} \quad$ Clinical lesions $>4 \mathrm{~cm}$ in size.

II The carcinoma extends beyond the cervix, but has not extended onto the pelvic wall; the carcinoma involves the vagina, but not as far as the lower third

IIA No obvious parametrial involvement.

IIB With parametrial involvement.

III The carcinoma has extended onto the pelvic wall; on rectal examination there is no cancer-free space between the tumour and the pelvic wall; the tumour involves the lower third of the vagina; all cases with a hydronephrosis or non-functioning kidney should be included, unless they are known to be due to other causes

IIIA No extension onto the pelvic wall, but involvement of the lower third of the vagina

IIIB Extension onto the pelvic wall or hydronephrosis or nonfunctioning kidney

IV The carcinoma has extended beyond the true pelvis or has clinically involved the mucosa of the bladder or rectum

IVA Spread of the growth to adjacent organs.

IVB Spread to distant organs.

Table 2. QUADAS-2 classifications

\begin{tabular}{|c|c|c|c|c|c|c|c|}
\hline Domain & $\begin{array}{l}\text { Signalling } \\
\text { question }\end{array}$ & $\begin{array}{l}\text { Signalling } \\
\text { question }\end{array}$ & $\begin{array}{l}\text { Signalling } \\
\text { question }\end{array}$ & $\begin{array}{l}\text { Signalling } \\
\text { question }\end{array}$ & $\begin{array}{l}\text { Signalling } \\
\text { question }\end{array}$ & Risk of bias & $\begin{array}{l}\text { Concerns for } \\
\text { applicability }\end{array}$ \\
\hline $\begin{array}{l}\text { 1. Patient se- } \\
\text { lection }\end{array}$ & $\begin{array}{l}\text { 1. Was a } \\
\text { consecutive or } \\
\text { random sam- } \\
\text { ple of patients } \\
\text { enrolled? }\end{array}$ & $\begin{array}{l}\text { 2. Did the } \\
\text { study avoid in- } \\
\text { appropriate } \\
\text { exclusions? }\end{array}$ & - & - & - & $\begin{array}{l}\text { Could the se- } \\
\text { lection of pa- } \\
\text { tients have in- } \\
\text { troduced bias? }\end{array}$ & $\begin{array}{l}\text { Is there con- } \\
\text { cern that the } \\
\text { included pa- } \\
\text { tients are not } \\
\text { representa- }\end{array}$ \\
\hline
\end{tabular}


Table 2. QUADAS-2 classifications (Continued)

tive of the patients who will receive the test in practice?

$\begin{array}{ll}\begin{array}{l}\text { Yes: The study } \\ \text { enrolled ran- }\end{array} & \text { Yes: All pa- } \\ \text { domly sam- } & \text { with clinically } \\ \text { pled or con- } & \text { deter- } \\ \text { sec- } & \text { mined FIGO } \\ \text { utive patients } & \text { stage 1A2 to } \\ \text { with clinically } & \text { IIA } \\ \text { deter- } & \text { cervical cancer } \\ \text { mined FIGO } & \text { were included } \\ \text { stage 1A2 } & \text { in the analysis } \\ \text { to IIA cervical } & \text { No: Patients } \\ \text { cancer } & \text { were excluded } \\ \text { No: The study } & \text { following ad- } \\ \text { en- } & \text { ditional triage } \\ \text { rolled selected } & \text { tests such as } \\ \text { patients. } & \text { computed to- } \\ \text { Unclear: This } & \text { mography or } \\ \text { was not clear } & \text { magnetic reso- } \\ \text { from the re- } & \text { nance scan } \\ \text { port. } & \text { imaging } \\ & \text { Unclear: This } \\ & \text { was not clear } \\ \text { from the re- }\end{array}$

Low risk: Low concern: 'yes' for all sig- the selected nalling ques- patients repretions. sent the pa-

High risk: 'no' tients or'unclear' for in whom the sigtests will be nalling ques- used in clinical tion 1 or 'no' practice for signalling (please see diquestion 2 Unclear: 'un- way, Figure 1) clear for sig- High concern: nalling ques- patient selection 2. tion was performed in such a way that the included participants did not represent patients in whom the tests will be used in clinical practice

\begin{tabular}{|c|c|c|c|c|}
\hline \multirow[t]{2}{*}{$\begin{array}{l}2 . \quad \text { Index } \\
\text { Test (Sentinel } \\
\text { node } \\
\text { detection and } \\
\text { analysis) }\end{array}$} & $\begin{array}{l}\text { 1. Were the in- } \\
\text { dex test results } \\
\text { interpreted } \\
\text { without } \\
\text { knowledge of } \\
\text { the results of } \\
\text { the } \\
\text { reference stan- } \\
\text { dard? (Refer- } \\
\text { ence standard } \\
\text { results } \\
\text { blinded) }\end{array}$ & $\begin{array}{l}2 . \\
\text { Did the study } \\
\text { provide a clear } \\
\text { definition of } \\
\text { what was con- } \\
\text { sidered to be a } \\
\text { "positive" and } \\
\text { result? }\end{array}$ & $\begin{array}{l}3 . \quad \text { Did } \\
\text { the study pro- } \\
\text { vide clear in- } \\
\text { formation } \\
\text { about which } \\
\text { cases were } \\
\text { considered to } \\
\text { be a "failure to } \\
\text { detect sentinel } \\
\text { nodes"? }\end{array}$ & $\begin{array}{l}\text { 4. Had test op- } \\
\text { erators had ap- } \\
\text { propriate } \\
\text { training? }\end{array}$ \\
\hline & $\begin{array}{l}\text { Yes: his- } \\
\text { tological anal- } \\
\text { ysis of sentinel } \\
\text { node was car- }\end{array}$ & $\begin{array}{l}\text { Yes: clear def- } \\
\text { inition for di- } \\
\text { agnosing sen- }\end{array}$ & $\begin{array}{l}\text { Yes: clear defi- } \\
\text { nition of "fail- } \\
\text { ure to }\end{array}$ & $\begin{array}{l}\text { Yes: clear in- } \\
\text { formation } \\
\text { regarding test }\end{array}$ \\
\hline
\end{tabular}

Could the Is there conconduct or in- cern that the terpretation of index test, its the index test conduct or inhave intro- terpreduced bias? tation differs from the review question?
Low risk: Low concern: 'yes' for all sig- the index test nalling ques- is conducted 
Table 2. QUADAS-2 classifications (Continued)

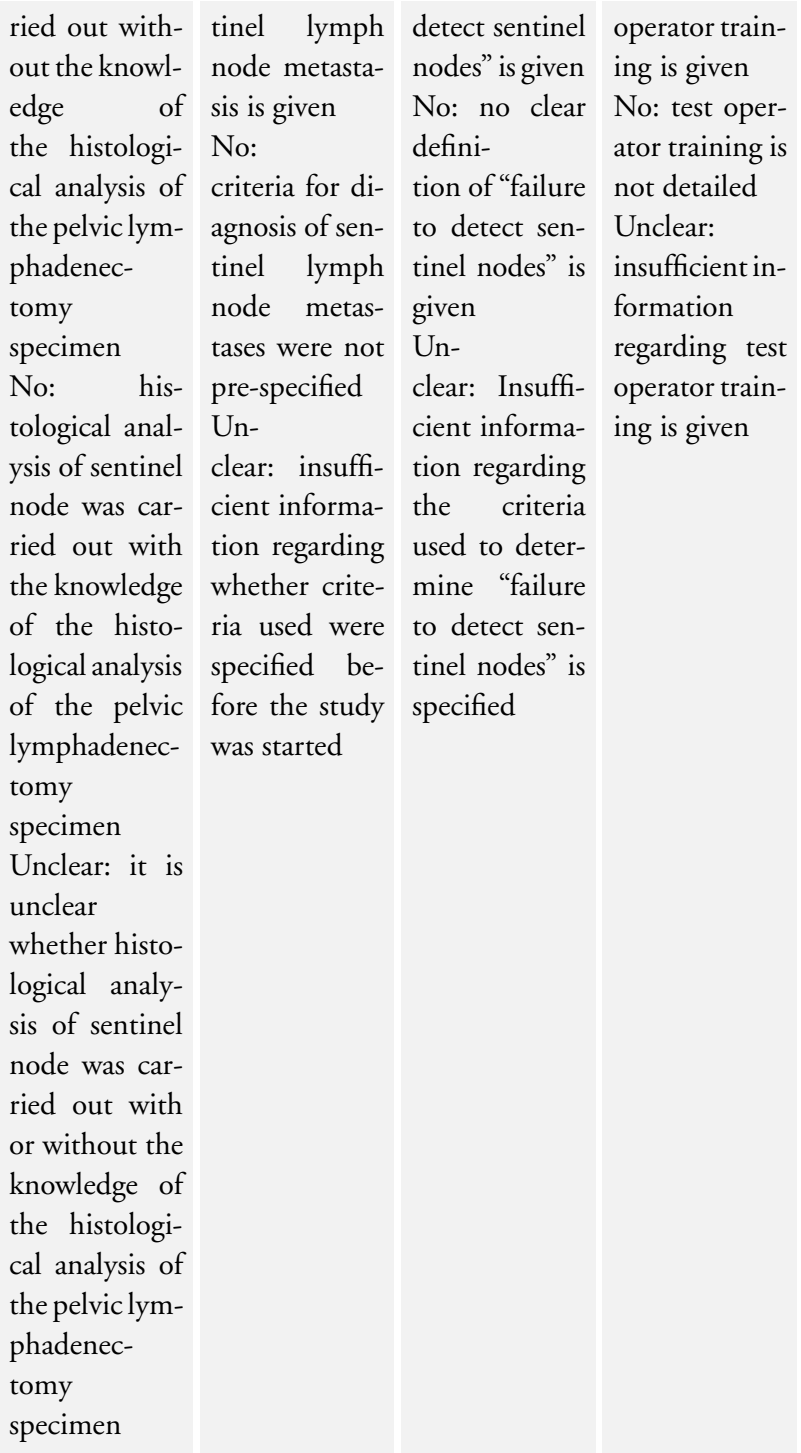

tions. and interHigh risk: 'no' preted in the or 'unclear' for way it is likely any one of sig- to be used in nalling ques- clinical practions 1,2 or 3 tice Unclear: 'no' High concern: or 'unclear' for the conduct or signalling interpretaquestion 4 tion of the index test differs from the way it is likely to be used in clinical practice
3. Refer- 1 . Is the refer- 2 . Were the 3.

ence standard ence standard reference stan- Did the study

(Pelvic lymph likely to cornode analysis) dard results in- provide a clear terpreted definition of without what was conknowledge of sidered to be the results of a "positive" rethe index test? sult? (Index test results blinded)
Could the ref- Are there conercerns that ence standard, the target conits conduct, or dition as deits interpreta- fined by the tion have in- reference stantroduced bias? dard does not match the review question? 
Table 2. QUADAS-2 classifications (Continued)

\begin{tabular}{|c|c|c|c|c|c|c|c|}
\hline & $\begin{array}{l}\text { Yes: all the pa- } \\
\text { tients received } \\
\text { standard } \\
\text { pelvic } \\
\text { lymphadenec- } \\
\text { tomy } \\
\text { No: some } \\
\text { or no patients } \\
\text { received stan- } \\
\text { dard pelvic } \\
\text { lymphadenec- } \\
\text { tomy } \\
\text { Unclear: sur- } \\
\text { gical extent of } \\
\text { lymphadenec- } \\
\text { tomy } \\
\text { is not reported } \\
\text { or could not } \\
\text { be clearly dis- } \\
\text { tinguished }\end{array}$ & $\begin{array}{l}\text { Yes: histologi- } \\
\text { cal analysis of } \\
\text { the pelviclym- } \\
\text { phadenec- } \\
\text { tomy spec- } \\
\text { imen was car- } \\
\text { ried out with- } \\
\text { out the knowl- } \\
\text { edge of } \\
\text { the histologi- } \\
\text { cal analysis of } \\
\text { sentinel node } \\
\text { No: histologi- } \\
\text { cal analysis of } \\
\text { the pelviclym- } \\
\text { phadenec- } \\
\text { tomy spec- } \\
\text { imen was car- } \\
\text { ried out with } \\
\text { the knowledge } \\
\text { of the histo- } \\
\text { logical analy- } \\
\text { sis of sentinel } \\
\text { node } \\
\text { Un- } \\
\text { clear: it is un- } \\
\text { clear whether } \\
\text { the histologi- } \\
\text { cal analysis of } \\
\text { the pelviclym- } \\
\text { phadenec- } \\
\text { tomy spec- } \\
\text { imen was car- } \\
\text { ried out with } \\
\text { or without the } \\
\text { knowledge } \\
\text { of histological } \\
\text { analysis of sen- } \\
\text { tinel node }\end{array}$ & $\begin{array}{l}\text { Yes: clear def- } \\
\text { inition for di- } \\
\text { ag- } \\
\text { nosing lymph } \\
\text { node metasta- } \\
\text { sis is given } \\
\text { No: cri- } \\
\text { teria for diag- } \\
\text { nosis of lymph } \\
\text { node metas- } \\
\text { tases were not } \\
\text { pre-specified } \\
\text { Un- } \\
\text { clear: insuffi- } \\
\text { cient informa- } \\
\text { tion regarding } \\
\text { whether crite- } \\
\text { ria used were } \\
\text { specified be- } \\
\text { fore the study } \\
\text { was started }\end{array}$ & - & - & $\begin{array}{l}\text { Low risk: } \\
\text { 'yes' for all sig- } \\
\text { nalling ques- } \\
\text { tions. } \\
\text { High risk: 'no' } \\
\text { for signalling } \\
\text { questions } 1 \text { or } \\
2 . \text { 'No' or 'un- } \\
\text { clear' for sig- } \\
\text { nalling ques- } \\
\text { tion } 3 \\
\text { Unclear: 'un- } \\
\text { clear for sig- } \\
\text { nalling ques- } \\
\text { tions } 1 \text { or } 2 \text {. }\end{array}$ & $\begin{array}{l}\text { Low concern: } \\
\text { the } \\
\text { reference stan- } \\
\text { dard is con- } \\
\text { ducted and in- } \\
\text { terpreted } \\
\text { in the way it is } \\
\text { used in clinical } \\
\text { practice } \\
\text { High concern: } \\
\text { the conduct or } \\
\text { interpreta- } \\
\text { tion of the in- } \\
\text { dex test differs } \\
\text { from the way } \\
\text { it is used in } \\
\text { clinical prac- } \\
\text { tice }\end{array}$ \\
\hline $\begin{array}{l}\text { 4. Flow and } \\
\text { Timing }\end{array}$ & $\begin{array}{l}\text { 1. Was there } \\
\text { an appropriate } \\
\text { interval } \\
\text { between index } \\
\text { test and refer- } \\
\text { ence standard? }\end{array}$ & $\begin{array}{l}\text { 3. Did all pa- } \\
\text { tients receive a } \\
\text { reference stan- } \\
\text { dard? }\end{array}$ & $\begin{array}{l}\text { 3. Did pa- } \\
\text { tients receive } \\
\text { the same refer- } \\
\text { ence standard? }\end{array}$ & $\begin{array}{l}4 . \quad \text { Were } \\
\text { all patients in- } \\
\text { cluded in the } \\
\text { analysis? }\end{array}$ & $\begin{array}{l}\text { 5. Were with- } \\
\text { drawals from } \\
\text { the study ex- } \\
\text { plained? }\end{array}$ & $\begin{array}{l}\text { Could the pa- } \\
\text { tient flow have } \\
\text { introduced } \\
\text { bias? }\end{array}$ & - \\
\hline
\end{tabular}


Table 2. QUADAS-2 classifications (Continued)

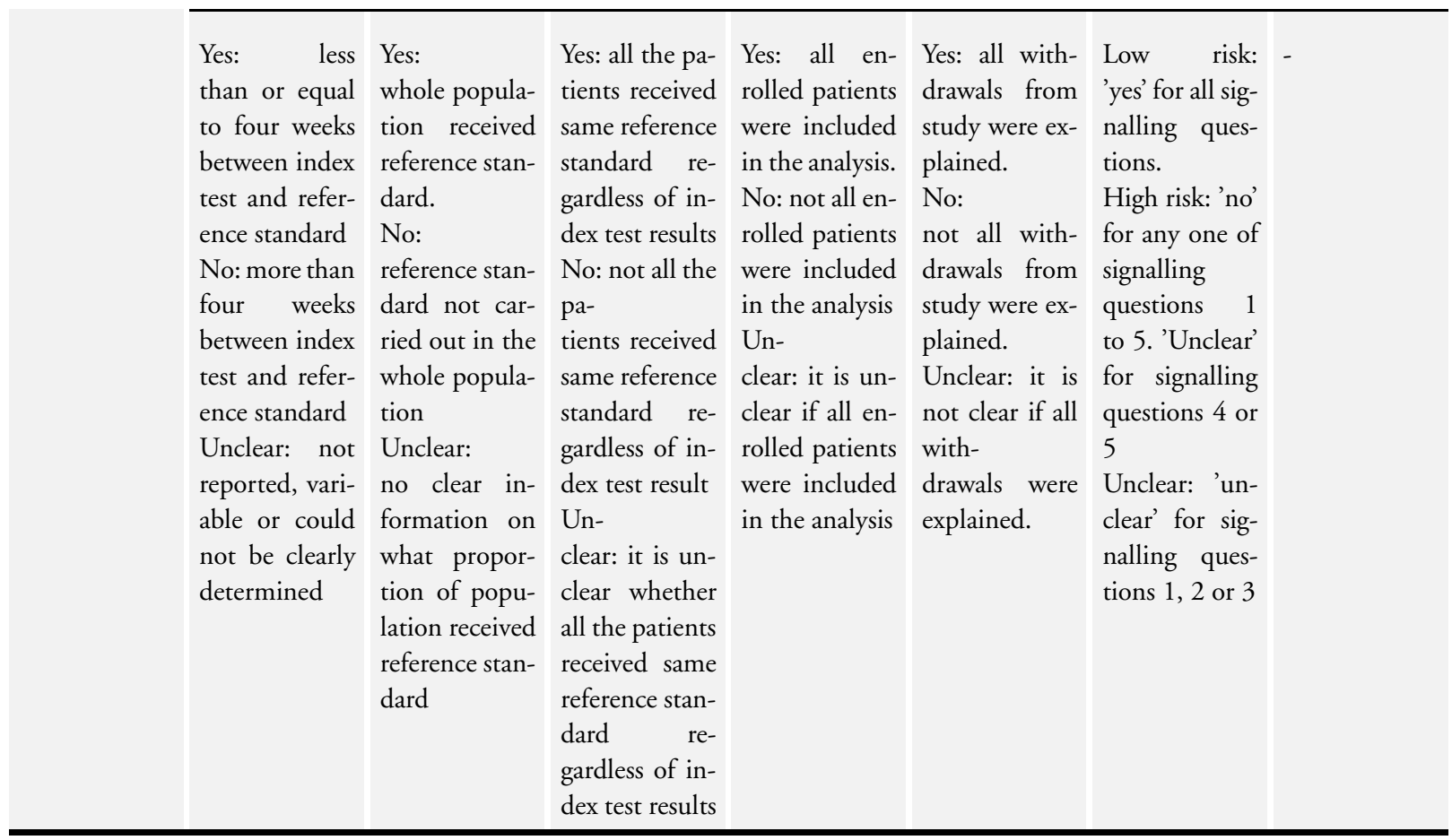

\section{A P P E N D I C E S}

\section{Appendix I. MEDLINE search strategy}

1. exp Lymph Nodes/

2. (lymph* adj (node* or nodal)).ti,ab.

3. (lymph* adj3 (mapping or spread* or staging)).ti,ab.

4. lymphadenopath*.ti,ab.

5. or $/ 1-4$

6. Pelvis/

7. (pelvic or pelvis).ti,ab.

8. Cervix Uteri/

9. (cervix or cervical or cervico*).ti,ab.

10. or/6-9

11. 5 and 10

12. Lymphatic Metastasis/ or (lymph* adj3 (metasta* or micrometasta*)).ti,ab.

13. 12 and 10

14. (neoplas* or cancer* or carcinoma* or malignan* or metasta* ${ }^{*}$ or micrometasta* or carcinogen* ${ }^{*}$ or adenocarcinoma* or $^{*}$ carcinosarcoma* or adenosquamous).ti,ab.

15. Neoplasm Staging/ or Neoplasm Invasiveness/ or Neoplasm Micrometastasis/

16. 14 or 15

Sentinel node biopsy for diagnosis of pelvic lymph node involvement in early stage cervical cancer (Protocol)

Copyright @ 2017 The Cochrane Collaboration. Published by John Wiley \& Sons, Ltd. 
17. 16 and 11

18. Uterine Cervical Neoplasms/

19. exp Uterine Cervical Dysplasia/

20. Cervical Intraepithelial Neoplasia/

21. or $/ 18-20$

22. 21 and (5 or 12$)$

23. 22 or 17 or 13

24. Sentinel Lymph Node Biopsy/

25. (sentin?l adj3 node*).ti,ab.

26. (lymphoscintigraph* or lymphoscintigram*).ti,ab.

27. Lymphography/

28. scintiphotograph*.ti,ab.

29. (scintigraph* or scintigram*).ti,ab.

30. (gamma camera adj imag*).ti,ab.

31. (radioisotope* adj scan*).ti,ab.

32. gamma probe.ti,ab.

33. (radioactive adj3 (tracer* or isotope $\left.^{*}\right)$ ).ti,ab.

34. (near infrared adj3 (fluorescen* or imag* or endoscop* or spectroscop*)).ti,ab.

35. (NIR adj3 (fluorescen* or imag* or endoscop* or spectroscop*)).ti,ab.

36. Spectroscopy, Near-Infrared/

37. Indocyanine Green/

38. (Technetium or Tc $99 \mathrm{~m}$ or $99 \mathrm{mTC}$ or blue dye* or patent blue or indocyanine green or methylene blue or isosulfan or iso sulfan or lymphazurin blue or radiocolloid or fluorescen* dye*).ti,ab,nm.

39. Technetium Tc 99m Sulfur Colloid/

40. Rosaniline Dyes/

41. Coloring Agents/

42. Methylene Blue/

43. Fluorescent Dyes/

44. Gamma Cameras/

45. or/24- 44

46. 23 and 45

47. exp animals/ not humans.sh.

48. 46 not 47

\section{Appendix 2. Embase search strategy}

1 pelvis lymph node/

2 lymph node/ or sentinel lymph node/

3 (lymph* adj (node* or nodal)).ti,ab.

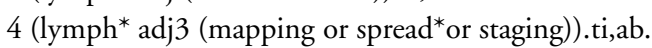

5 lymphadenopath*.ti,ab.

6 or $/ 2-5$

7 pelvis/

8 (pelvic or pelvis).ti,ab.

9 exp Uterine Cervix/

10 (cervix or cervical or cervico*).ti,ab.

11 or/7-10

126 and 11

131 or 12

14 exp lymph node metastasis/ or (lymph* adj3 (metasta* or micrometasta*)).ti,ab.

1514 and 11

Sentinel node biopsy for diagnosis of pelvic lymph node involvement in early stage cervical cancer (Protocol)

Copyright ( 2017 The Cochrane Collaboration. Published by John Wiley \& Sons, Ltd. 
16 (neoplas* or cancer* or carcinoma* or malignan* or metasta* or micrometasta* or carcinogen* or adenocarcinoma* or carcinosarcoma* or adenosquamous).ti,ab.

17 Cancer Staging/ or Tumor Invasion/

18 or/16-17

1918 and 13

20 exp uterine cervix tumor/

21 exp uterine cervix dysplasia/

22 or $/ 20-21$

2322 and ( 1 or 6 or 14$)$

2423 or 13 or 15

25 sentinel lymph node biopsy/ or (sentin?l adj3 node* adj3 biops*).ti,ab.

26 lymphoscintigraphy/

27 lymphography/

28 scintillation camera/ or gamma camera/

29 exp tumor scintiscanning/

30 (lymphoscintigraph* or lymphoscintigram*).ti,ab.

31 scintiphotograph*.ti,ab.

32 (scintigraph* or scintigram*).ti,ab.

33 (gamma camera adj imag*).ti,ab.

34 (radioisotope* adj scan*).ti,ab.

35 gamma probe.ti,ab.

36 (radioactive adj3 (tracer* or isotope*)).ti,ab.

37 (Technetium or Tc 99m or 99mTC or blue dye* or patent blue or indocyanine green or methylene blue or disulfine blue or isosulfan or iso sulfan or lymphazurin blue or radiocolloid or fluorescen* dye*).ti,ab.

38 (near infrared adj3 (fluorescen* ${ }^{*}$ imag* $^{*}$ or endoscop* or spectroscop*)).ti,ab.

39 (NIR adj3 (fluorescen* or imag* or endoscop* or spectroscop*)).ti,ab.

40 Near infrared spectroscopy/ or fluorescence spectroscopy/ or fluorescence imaging/

41 indocyanine green/

42 technetium sulfur colloid tc $99 \mathrm{~m} /$

43 methylene blue/

44 disulfine blue/

45 fluorescent dye/

46 coloring agent/

47 fuchsine/

48 or/25-47

4924 and 48

50 (animal.hw. or nonhuman/) not human/

51 (veterinary or animal or animals or feline or canine or tierheilkunde).jw.

52 (cat or cats or dog or dogs or beagle or beagles or rat or rats or rodent or rodents or mouse or mice or murine or rabbit or rabbits or pig or pigs or bitch or bitches or feline or canine or swine or porcine or sheep or hamster or hamsters or cattle or bovine or monkey or monkeys or macaque or macaques).ti.

53 or $/ 50-52$

5449 not 53

Sentinel node biopsy for diagnosis of pelvic lymph node involvement in early stage cervical cancer (Protocol) 
WHAT'S NEW

\begin{tabular}{ll|l}
\hline Date & Event & Description \\
\hline 14 November 2017 & Amended & $\begin{array}{l}\text { A new team of authors updated the text of the protocol adding new } \\
\text { citations and a reference to Quadas-2 quality assessment criteria }\end{array}$ \\
\hline 14 November 2017 & New citation required and minor changes & $\begin{array}{l}\text { Update of clinical descriptive sections following local review and } \\
\text { revisions to DTA methods }\end{array}$ \\
\hline
\end{tabular}

\section{CONTRIBUTIONSOFAUTHORS}

All of the review authors contributed to the conception and design of the study, acquisition and interpretation of the data, and drafting and revising of the protocol.

\section{DECLARATIONSOF INTEREST}

None known.

\section{SOURCES OF SUPPORT}

\section{Internal sources}

- No sources of support supplied

\section{External sources}

- Department of Health, UK.

NHS Cochrane Collaboration programme Grant Scheme CPG-506 